\title{
A comparative study between kessler suture versus polypropylene mesh implantation to repair tenotomized common calcaneal tendon in rabbits
}

\author{
S.Kh. Humadi \\ Department of Veterinary Surgery, College of Veterinary Medicine, Tikrit University, Tikrit, Iraq \\ email: dr.saddamkh@gmail.com
}

(Received September 15, 2018; Accepted November 8, 2018)

\begin{abstract}
The present study is assigned to throw the light on the benefit of using Kessler suture compared with polypropylene mesh implantation in healing of induced tenotomy of common calcaneal tendon in a rabbit model based on clinicohistopathological evaluation. Twenty adults New Zealand white male rabbits were used for this clinical prospective study divided equally and randomly into two groups. The first group, (suture group $n=10$ ) and the second group (mesh group $\mathrm{n}=10$ ). Under the effect of general anesthesia, longitudinal skin incision over the common calcaneal tendon was made, and the skin flap was reflected. The tendon was isolated by blunt dissection from the surrounding tissue, with small curved forceps. Simulation of a rabbit's common calcaneal tendon rupture was made by sharp transvers incision with scalpel. The first group repair with (Kessler Suture) using polypropylene suture size 4.0. In contrast, the second group repair with (polypropylene mesh implantation) after initial suturing of the cut ends of tendon by two simple interrupted stitches using polyglyconate suture size 4.0. The surgical skin wounds were re-stitched by simple interrupted pattern with 3-0 silk. After clinical follow-up of the treatment rabbits, certain secondary health problems were encountered represented by swelling of operative site and lameness. Grossly, adhesions were noticed between the tendon and subcutaneous tissue in rabbits of both groups. Microscopical examination reflected presence of inflammatory cells perivascular edema and few capillaries at two months. At the end of experiment there were perfect orientation and organization of collagen fibers in mesh group in comparing with suture group. Based on the results obtain from this study, it seemed that both groups reflected best outcome in healing of operated tendons with superiority of mesh group in comparing with suture group.
\end{abstract}

Keywords: Common calcaneal tendon, Rupture, Kessler suture, Mesh, Rabbits Available online at http://www.vetmedmosul.com

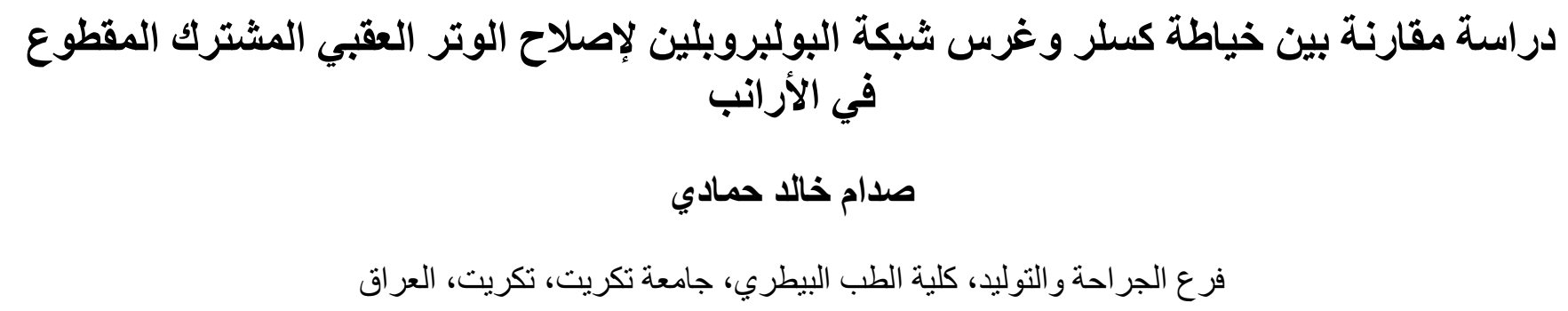

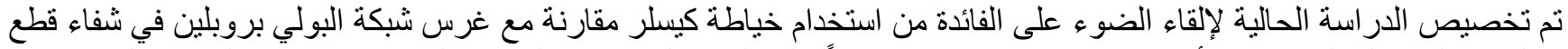

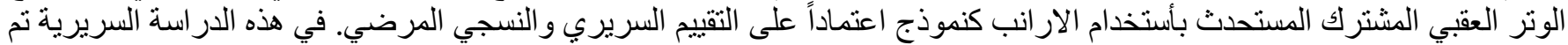

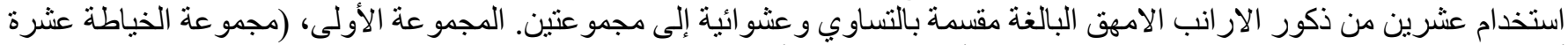
أرانب) و المجموعة الثانية (مجموعة الثبكة عشرة أرانب). تحت تأثير التخدير العام، تم إجراء جرح جلدي طولي فوق الوتر، وعزل 


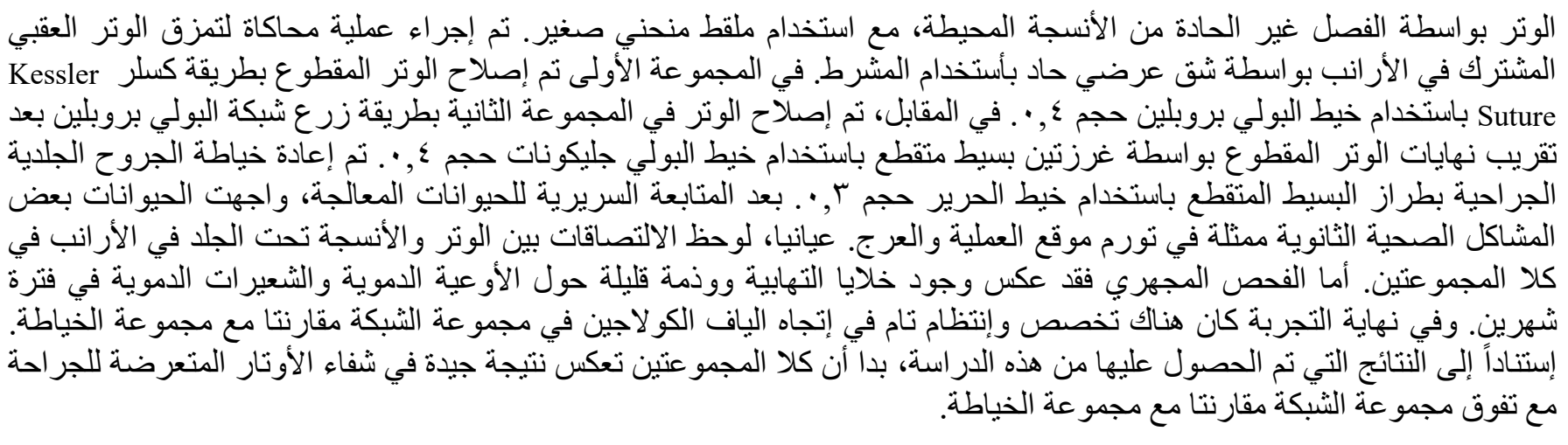

\section{Introduction}

The etiology of common calcaneal tendon injuries is usually traumatic which may result in acute rupture of the tendon with partial or complete loss of integrity of the structure (1). In addition, weakening or rupture of the tendon structure can occur secondarily to systemic diseases (e.g. Cushing's disease) or to iatrogenic etiologies (2). The clinical signs associated with the rupture of common calcaneal tendon will vary depending on the severity of the injury, but the swelling around the tendon insertion on the hock is the main symptom (3).

The surgical techniques which are involved suturing may lead to complications such as early or late tendon adhesions and scar formation. Additionally, sutures may slip through the tendon and loosen due to parallel orientation of tendon fibers or may cause local ischemia due to wrap by sutures all-around of the tendon (4).

The golden aim at tendon repair is to establish a permanent repair that could withstand significant tensile strength loads and to glide smoothly without any interference against movement. Healing of tendon is slow and may require long period (9-12 months or more in some cases) due to its poor vascularity (5). Recently, multifactorial strategies treatments for common calcaneal tendon lesions are used such as application of prosthetic meshes which act as a scaffold to conduct the two cut ends of the tendon. In addition, stability of the rupture site, they should be porous to facilitate cells migration and proliferation and movement of growth factors (6). Other treatment choices include tendon transplantation, Laser, shock wave therapy, stem cells, platelet rich plasma, autologous conditioned plasma, autologous conditioned serum and cells therapy (7-9). The study aimed to compare the efficacy of Kessler suture and polypropylene meshes implantation to repair tenotomized common calcaneal tendon tendons in rabbits based on clinico-pathological evaluation.

\section{Materials and methods}

For this in vivo study, 20 adults' male rabbits' specific pathogen free, aged 8-10 months and weighing1.500 $\pm 1.750 \mathrm{~kg}$ was enrolled for this research. They were placed in standard rabbit cages, under the same conditions with standard pellet diet. Rabbits were randomly allocated into two equal groups. The first group (suture group) and the second group (mesh group). All animals were acclimatized to their environment for 2 weeks.

Rabbits were fasted for 12 hours prior to the operation and had free access to water, then anesthetized using a combination of ketamine hydrochloride $10 \%$ (Claris, India) at a dose rate of $35 \mathrm{mg} / \mathrm{kg} \mathrm{B.W}$ and xylazine hydrochloride $2 \%$ ( $2 \%$ xylo-Germany) at a dose rate of $5 \mathrm{mg} / \mathrm{kg} \mathrm{B.W}$ administered via intramuscular route (10). The site was prepared for aseptic surgery. The animal placed on right recumbency with operated limb up, skin incision approximately $5 \mathrm{~cm}$., in length was made over the common calcaneal tendon. The tendon was isolated from the underlying tissue by blunt dissection (Figure 1). A fullthickness transverse incision of common calcaneal tendon was performed in its mid-portion (Figure 2).

In the first group, tenorrhaphy of common calcaneal tendon was immediately performed by using Kessler suture technique as described by Fridman et al. (11). The sharply cut tendon ends were approximated centrally and sutured using a non-absorbable synthetic monofilament thread (polypropylene 4-0) (Figure 3). In polypropylene mesh group, after initial suturing of the cut ends of tendon by two simple interrupted stitches using polyglyconate suture size 4.0 , a polypropylene mesh was wrapped around the cut ends and fixed to tendon core with 4-0 polypropylene suture in simple interrupted pattern (Figure 4). After compilation of suture and meshes implantation, the skin was closed by 3-0 silk with simple interrupted pattern. Sterile bandage was used to cover the skin wound which changes every two days till removal of the skin stitches. Broad spectrum antibiotic represented by pencillin- 
streptomycine in a dose of 20000 I.U and $10 \mathrm{mg} / \mathrm{kg} \mathrm{B.W.,}$ respectively was injected IM for five consecutive days.

The clinical evaluations consisted monitoring the degree of lameness and local swelling with increased diameter of the operated leg each three days till day 18 .

Macroscopic and microscopic evaluation: This was performed at two- and four-months post-operation. For macroscopic evaluation, the repair site was visually examined to determine any changes in the tendons and the severity of peritendinous adhesions which may happen between the tendon and surrounding tissue. Adhesions were quantified into five grades (0-4) as mentioned by $\mathrm{Bu}$ rgisser et al. (12).

For microscopic examination: tendon Biopsies $\left(1 \mathrm{~cm}^{3}\right)$ were collected from (20) rabbits (10 rabbits for each group) and (5 rabbits / period) at two- and four-months posttendons repair. Biopsies were fixed in $10 \%$ neutral buffered formalin, the tissue sections at 5-6 $\mu \mathrm{m}$ thick were routinely prepared and stained by Hematoxylin and Eosin (13).

The statistical analysis was conducted by the aid of SAS (2004) program. All data observations were expressed as Mean \pm Standard Error $(\mathrm{M} \pm \mathrm{SE})$ and differences between the two groups were compared using one-way Analysis of Variance (ANOVA). Least significant difference (LSD) was used to compare between means. The level $P \leq 0.05$ was considered to be significant (14).

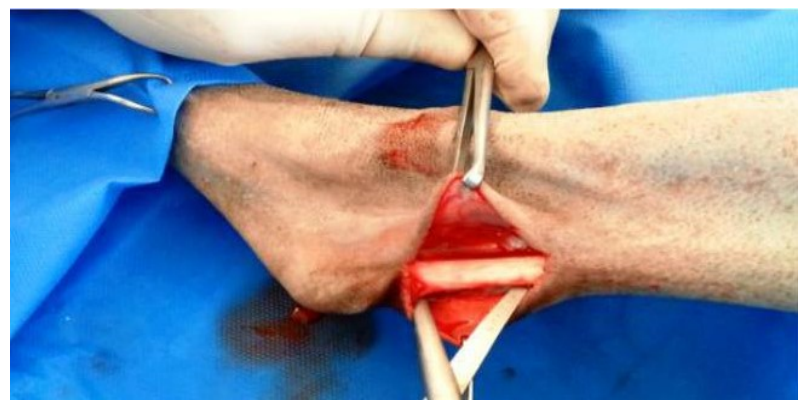

Figure 1: Skin is incised and blunt dissection is made to separate the tendon from the surrounding structures.

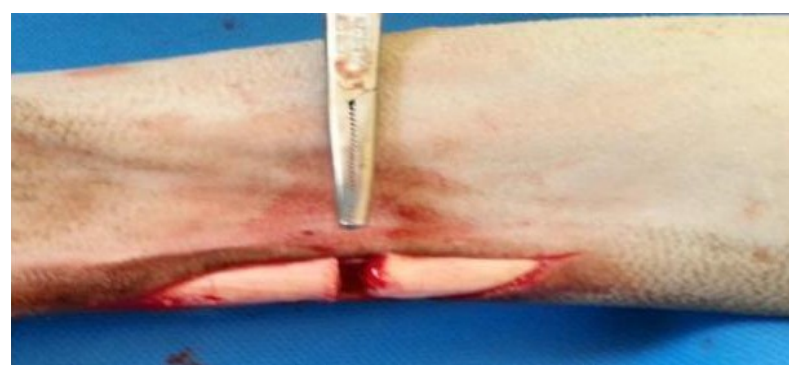

Figure 2: Common calcaneal tendon is transected in its mid portion.

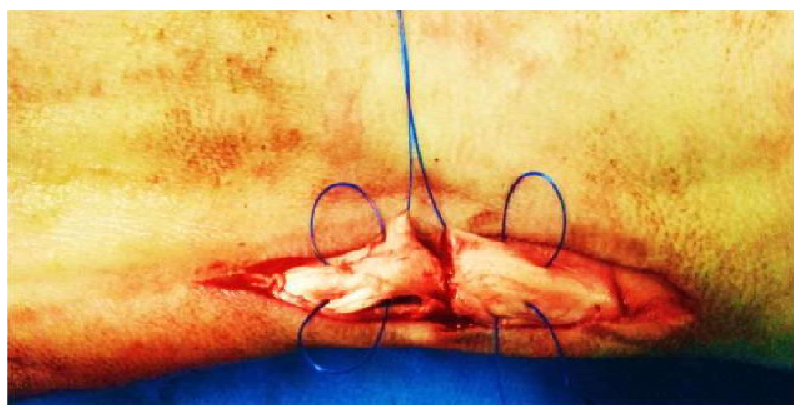

Figure 3: Suturing of common calcaneal tendon with Kessler pattern (two loops on each side).

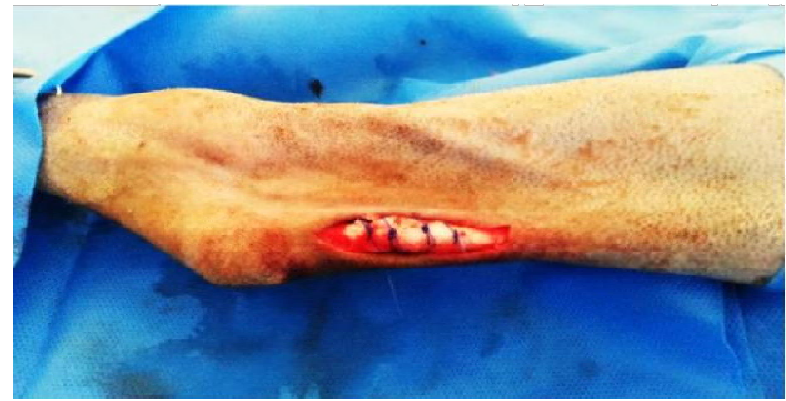

Figure 4: Polypropylene mesh is fixed to the tendon core with simple interrupted stitches of polypropylene thread.

\section{Results}

There were no intraoperative complications. All rabbits showed good general health status. All skin wounds healed normally within 10 days post-surgery. After clinical followup all animals showed lameness with significant differences $P<0.05$ between the two groups during the day three with (score 3.5) in the suture group and (score 3.0) in mesh group and the animals cannot bear weight on the operative limb. Furthermore, with the progress of post-operative duration lameness were decreased and rapid absence of lameness was noticed in mesh group at day 12 (score 0 ) and at day 18 in suture group (Table 1).

Another pathognomonic sign was local swelling at the operative site which was seen in all treated rabbits. The mean value of swelling was reached to its peak at day 9 (9 $\mathrm{cm})$ in suture group and $(8.0 \mathrm{~cm})$ in mesh group with significant differences $(\mathrm{P}<0.05)$ between them. Then swelling was declined starting from day 12 and retained to its normal values in day 15 and 18 in mesh and suture groups respectively and swelling diminished spontaneously with no any treatment (table 2).

Also, local swelling at the operative site was seen in all treated rabbits which lasted for few days. Swelling was moderate in suture group and mild in mesh group and 
remitted faster in the later. No any treatment was used and swelling diminished spontaneously.

Table 1 . Shows the mean values of lameness scores of first and second groups.

\begin{tabular}{cccl}
\hline Days & $\begin{array}{c}\text { Suture group } \\
\text { score } \\
\mathrm{X} \pm \mathrm{S} \mathrm{E}\end{array}$ & $\begin{array}{c}\text { Mesh group } \\
\text { score } \\
\mathrm{X} \pm \mathrm{S} \mathrm{E}\end{array}$ & $\begin{array}{c}\text { LSD } \\
\text { value }\end{array}$ \\
\hline 0 & Zero aA & Zero aA & \\
3 & $4.0 \mathrm{bA}$ & $3.0 \mathrm{bB}$ & \\
6 & $3.0 \mathrm{cA}$ & $2.0 \mathrm{cB}$ & \\
9 & $2.0 \mathrm{dA}$ & $1.0 \mathrm{~dB}$ & 0.728 \\
12 & $1.5 \mathrm{eA}$ & $0.0 \mathrm{eB}$ & \\
15 & $0.5 \mathrm{fA}$ & $0.0 \mathrm{eA}$ & \\
18 & $0.0 \mathrm{fA}$ & $0.0 \mathrm{eA}$ & \\
\hline $\mathrm{LSD}=$ & \multicolumn{3}{c}{0.615} \\
\hline
\end{tabular}

Zero $=$ day prior to operation. Capital letters denote differences $\mathrm{P}<0.05$ between the two groups. Small letters denote differences $\mathrm{P}<0.05$ between animals of the same group.

Table 2. Shows the mean values of swelling $(\mathrm{cm})$ of suture and mesh groups.

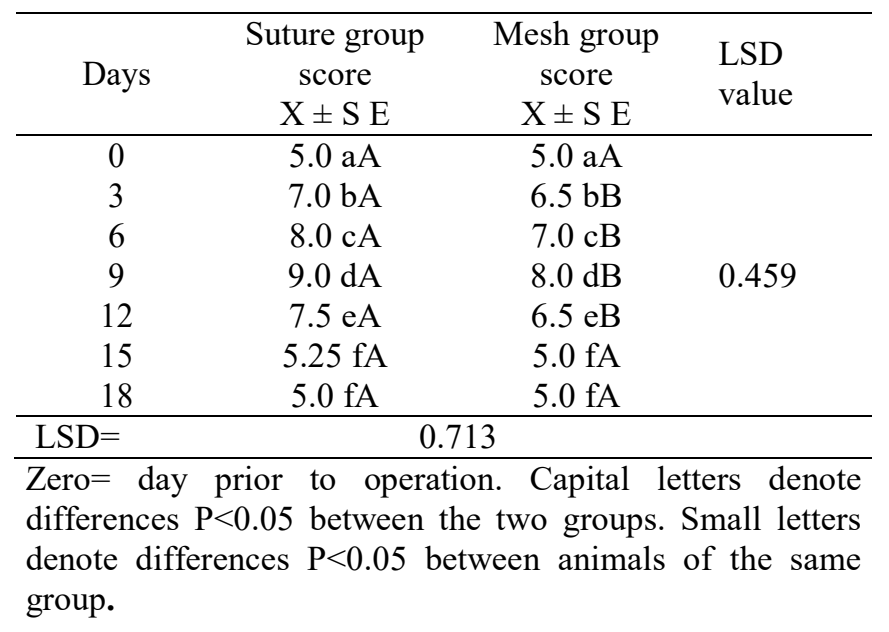

In gross examination the pathognomonic findings of the tendons at (two and four months) was the adhesion between the tendon and the overlying skin in both groups. At two months in suture group, there were adhesions $(80 \%)(n=3$ severe and $\mathrm{n}=1$ moderate adhesions) noticed between common calcaneal tendon and subcutaneous tissue. In contrast mesh group, showed low ratio $40 \%$ ( $\mathrm{n}=2$ moderate adhesion) (Table 3 and figures 5 and 6). At four months, the ratio of adhesions were decreased in suture group $(n=3)$. In mesh group ( $\mathrm{n}=1$ mild case) (Table 4$)$.
Table 3. Shows the adhesions at two months post-treatment in the two groups

\begin{tabular}{lcccc}
\hline \multirow{2}{*}{ Groups } & \multirow{2}{*}{$\begin{array}{l}\text { No. of } \\
\text { affected } \\
\text { animals }\end{array}$} & \multicolumn{3}{c}{ Severity of adhesion (grade 1-3) } \\
\cline { 3 - 5 } & 1 (mild) & 2 (moderate) & 3 (severe) \\
\hline Suture & 4 & - & 1 & 3 \\
Mesh & 2 & - & 2 & - \\
\hline
\end{tabular}

Table 4. Shows the adhesions at four months post-treatment in the two groups

\begin{tabular}{|c|c|c|c|c|}
\hline \multirow{2}{*}{ Groups } & \multirow{2}{*}{$\begin{array}{l}\text { No. of } \\
\text { affected } \\
\text { animals }\end{array}$} & \multicolumn{3}{|c|}{ Adhesion grade } \\
\hline & & 1 (mild) & 2 (moderate) & 3 (severe) \\
\hline Suture & 3 & 1 & 1 & 1 \\
\hline Mesh & 1 & 1 & - & - \\
\hline & & & & \\
\hline & & & & \\
\hline & & & & \\
\hline & & & & \\
\hline & & & & \\
\hline & & & & \\
\hline
\end{tabular}

Figure 5: Shows the adhesion in suture group, two months post-suturing.

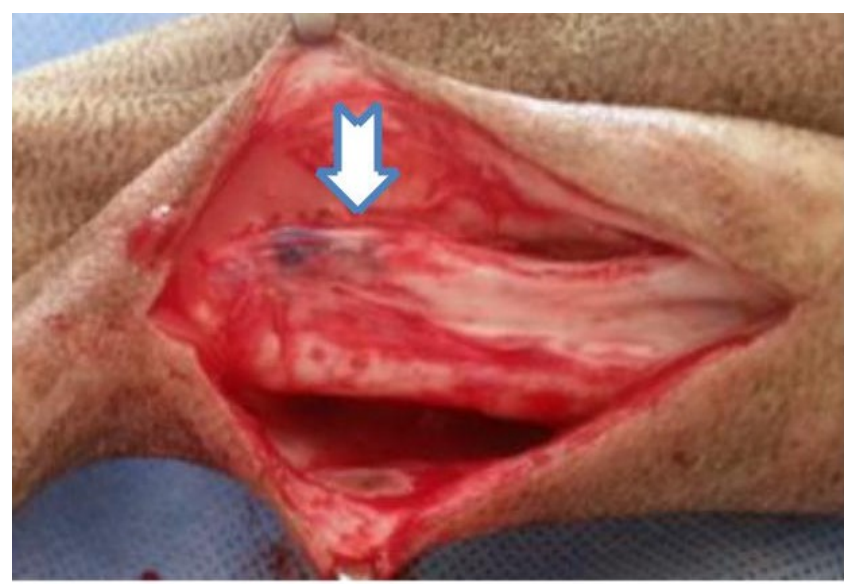

Figure 6: Shows the adhesion in mesh group, two months post-implantation. 
Table 5: The histopathological features of tendons of suture and mesh groups

\begin{tabular}{cll}
\hline Time & \multicolumn{1}{c}{ Suture group } & \multicolumn{1}{c}{ Mesh group } \\
\hline Two months & $\begin{array}{l}\text { Presence of inflammatory cells and } \\
\text { perivascular edema (Figure 7). }\end{array}$ & $\begin{array}{l}\text { Regular collagen fibers and presence of few capillaries } \\
\text { (Figure 8). }\end{array}$ \\
Four months & $\begin{array}{l}\text { Regular organization of collagen fibers and } \\
\text { moderate increase in fibroblasts (Figure 9). }\end{array}$ & $\begin{array}{l}\text { Regular orientation of collagen fibers and tenocytes } \\
\text { which have cigar shaped nuclei are arranged along the } \\
\text { longitudinal axis of the tendon (Figure 10). }\end{array}$ \\
\hline
\end{tabular}

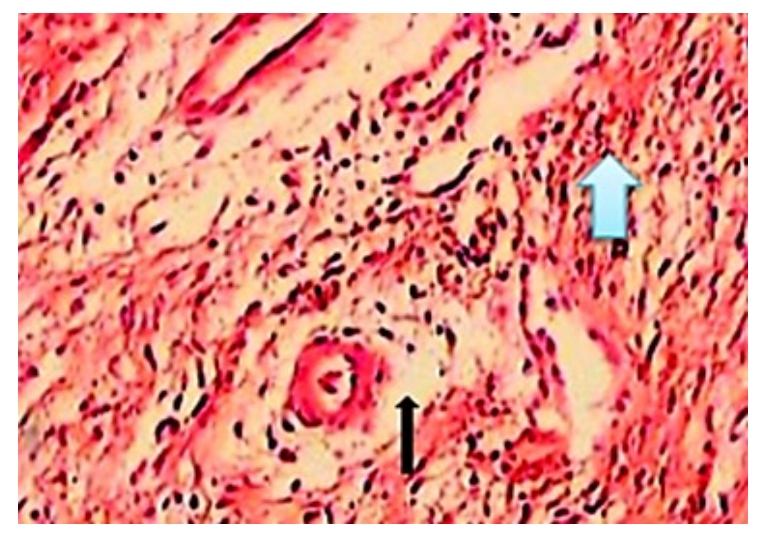

Figure 7: Tendon of suture group, 2 months post-surgery show inflammatory cells (thick arrow) and perivascular edema (thin arrow) (HE, X100).

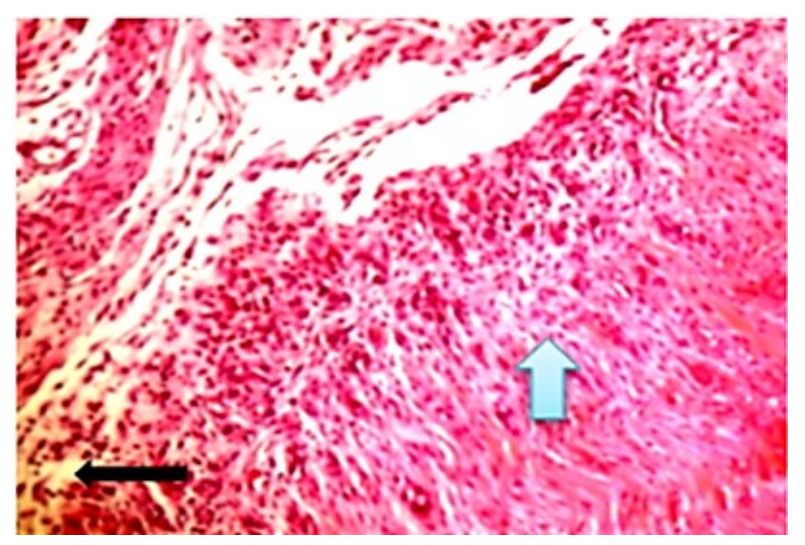

Figure 8: Tendon of mesh group, 2 months post-surgery show regular collagen fibers (thick arrow) and presence of few capillaries (thin arrow) (HE, X100).

\section{Discussion}

Tendon injuries still remain an orthopedic challenge. The time-consuming healing process extends over many months and usually leads to a reparative scar tissue. Scars provide inferior biomechanical stability. Also, the poor blood supply and hypo-cellular property of the tendons are thought to be major reasons for their limited self-healing properties (15).

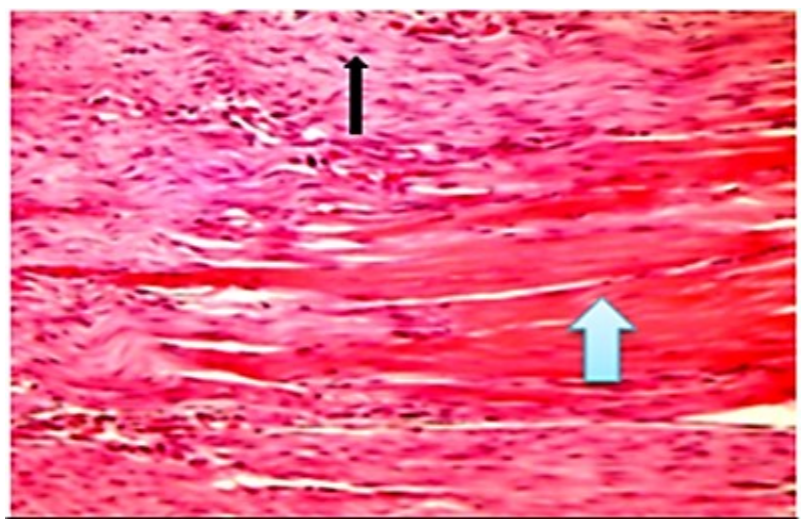

Figure 9: Tendon of suture group, 4 months post-surgery show regular organization of collagen fibers (thick arrow) and moderate increase in fibroblasts (thin arrows) (HE, $\mathrm{X} 100)$.

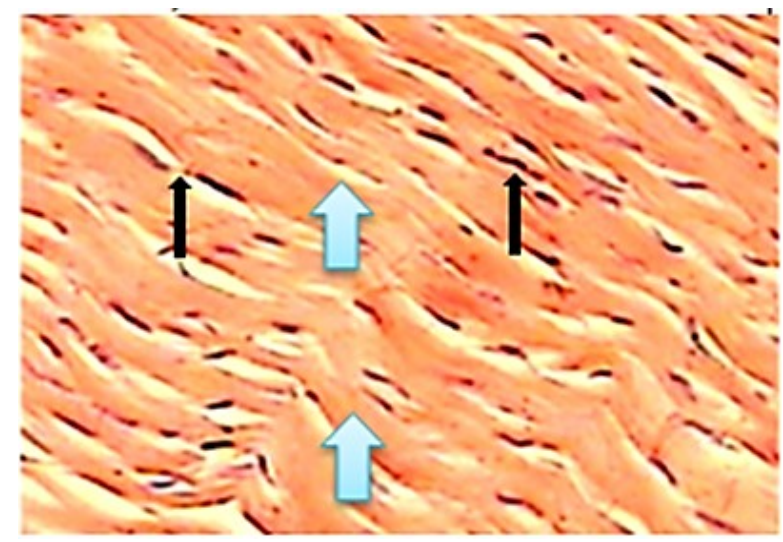

Figure 10: Tendon of mesh group, 4months post-surgery show regular orientation of collagen fibers (thick arrows) and tenocytes which have cigar shaped nuclei (thin arrows) are arranged along the longitudinal axis of the tendon (HE, $\mathrm{X} 100)$.

During a follow-up of treatment animals there were no any serious complications such as (infection, failure of tendon repair or death) this may be attributed to strike aseptic technique beside good post-operative follow-up. The present study reflected few minor non-specific 
secondary health problems represented by local swelling of operative site. This compliment may ascribe to intratendinous hematoma, edema and influx of inflammatory cells, as a part of the inflammatory process. In an experimental study by Maffulli (16) recorded seroma, fever, erythema of the operative area and wound dehiscence due to infection. Lameness noticed in the current study may be related to pain evocated from inflammation and cutting of the nerves in the operative site. A study by Alfredson et al. (17) who indicated that chemical irritants and neurotransmitters may generate pain in tendinopathy due to increase in levels of lactic acid.

A number of surgical techniques have been described for repair of tendon ruptures such as suturing, autogenously grafts or free fascia may be used when the gaps are manageable. Synthetics meshes or grafts are useful when autogenous grafts cannot be used (18).

The goals of successful tenorrhaphy include creating a strong repair and restoring gliding function to the tendon with minimal gap formation, negligible adhesion formation, should not adversely affect the tendon vasculature $(19,20)$.

The suture material selected should be inert, strong easy to pass through tissues and should maintain tensile strength until the anastomosis has its own strength (21).

Polypropylene (4-0) used in the current study has been described as the most appropriate suture material for tendon repair that comfortably passes through the tendon. Polypropylene is non-absorbable monofilaments, and whose reactivity is minimal (confirmed histologically in this study). Furthermore, polypropylene thread provided the desired tensile strength kept for years within the tissue till complete healing of the tendon and this come in line with (11). Non-absorbable synthesis sutures included monofilament nylon, and braided polyester have good biocompatibility when used in tendon repair. Higher tensile strength and stiffness was showed polypropylene than monofilament nylon and polyester (22).

The clinical results in rabbits by Mario et al. (23) were durable, no re-ruptures and good motion range after applying of synthetic mesh to repair tendon injury, these studies compatible with our result of no re-rupture in mesh group.

Also, lameness was recorded in a study by Maia (24), when used intra-lesional injection of Platelets Rich Plasma for treatment of superficial digital flexor tendonitis induce by splitting in equine model.

The macroscopic evaluations in our study showed no local adverse effects for either the suture or tested meshes. The meshes never showed any signs of degradation after four months and were macroscopically undetectable at this time. The same findings noticed by Dietrich et al. (25), whom used Platelet-Rich fibrin for accelerated healing of Achilles tendon in rat.
Adhesions were noticed macroscopically between common calcaneal tendon and S/C tissues. This may be ascribed to several factors which include trauma to the tendon and sheath from the initial injury, which resulted in inflammation and ischemia. Márcia et al. (26) referred that the major causes of adhesion are a tendon sheath defect after traumatic or surgical injury. The tendon sheath is a membrane-like structure, which acts like a biological barrier, preventing invasion of peripheral fibrotic tissue and inhibiting exogenous healing of tendon. When this barrier is damaged, the normal functionality of the tendon is jeopardized. Such complications compromise tissue properties, interfering with motion, gliding and consequently functionality.

In present study, the tendons of the rabbits at four months post- treatment especially in meshes implantation groups the adhesions rate at this period was lower than two months this may be resulted from a decrease in the formation of new extra cellular matrix due to the inhibition of mononuclear phagocytosis and lymphocytes.

Surgical mesh is commonly used for repairing ruptured tendons. The mesh was designed bridge the defect between tendon and act as a scaffold for the deposition and orientation of the tendon fibers. It has multiple pores that facilitate the growth of capillary network and consequently oxygen delivery as the collagen synthesis is an oxygen dependent process. The material was malleable, so it was easily handled and economically, its cost was low (27). The surgical mesh can be tailored to any size and shape to adapt the gap of tendon rupture and stitched together with surgical sutures. This gives surgeons another layer of flexibility to arrange and secure the mesh as needed on an individual basis (28). The conventional surgical mesh restored the mechanical continuity of the ruptured tendon and might provide a physical environment that stimulates tenogenesis $(29,30)$.

In current study the histopathological data revealed that wrapping the tenorrhaphy site with synthetic mesh accelerates the early repair response of common calcaneal tendon. The meshes facilitates the approximation of the ends of the tendon few days after injury, inflammation in tendon subsides and fibroblasts proliferation and biosynthesis of extracellular matrix and collagen fibers. In second group the tendon fibers were more organized as compared to the first group. The same was mentioned by Sharma and Maffulli (31), who indicated that the fragmentation of the implant caused transfer of the tensile loads and cause areas of stress that stimulate collagen synthesis thereby creating mature longitudinally oriented new tendon fibers filling the gap.

The results of our study revealed presence of blood vessels this may occur according to hypothesis that the injured tendon suffer decreased blood nutrition and hypoxia that activated macrophages to release angiogenic factors 
represented by vascular endothelial growth factor which initiate the angiogenesis in the injured site. Also, the endothelial cells aggregate in the granulation tissue which lead to proliferation and regeneration of blood vessels. This result agreed with Pufe et al. (32).

In current study, the sections of tendon showed proliferation of tenocytes this indicated that both intrinsic and extrinsic mechanisms are believed to contribute to the tendon healing process, this come in line with (33), who referred that tenocytes within the tendon and epitenon play an important role in the intrinsic mechanism, while in the extrinsic mechanism, inflammatory cells and fibroblasts from the overlying sheath and periphery are the main participants. In the present study the application of polypropylene meshes in rabbits revealed no signs of infection that proved its biocompatibility due to the inert nature of the material in which the mesh is made and its resistance to bacterial contamination, similar interpretation was mentioned by Campbell and Bailey (34).

In conclusion the use of synthetic non-absorbable meshes in our study had successes in acceleration of collagen deposition and act as scaffold that bridged the cut ends of the tendon, thus it increases their tensile strength and stability which was better and superior when compared with Kessler suture technique. On other hands polypropylene mesh is a successful substitution to autogenous graft in the treatment of common calcaneal tendon rupture.

\section{Acknowledgments}

I would like to thank dr. Mustafa Talib for his perfect technical assistance in the preparation and of the histopathological sections and highly acknowledged dr. Mohammed Hassan for photography.

\section{References}

1. Park YS, Sung KS. Surgical reconstruction of chronic Achilles tendon ruptures using various methods. Orthopedics. 2012;35:213-218. doi: 10.3928/01477447-20120123-13.

2. Jarvinen TA, Kannus P, Maffulli N, Khan KM. Achilles tendon disorders: etiology and epidemiology. Foot Ankle Clin. 2005;10:255266. DOI: 10.1371/journal.pone.0048978.

3. Butler DL, Juncosa N, Dressler MR. Functional efficacy of tendon repair processes. Annu Rev Biomed Eng. 2004;6:303-329. doi: 10.1146/annurev.bioeng.6.040803.140240

4. Ryan AR, Sorushanova PD, Zeugolis I. The past, present and future in scaffold-based tendon treatments. Advanced Drug Delivery Reviews. 2015;84:257-277. DOI: 10.1016/j.addr.2014.11.022.

5. Forslund C. Treatment for improving tendon repair. Studies on rat and rabbit Achilles tendons. Acta Orthop Scand Suppl. 2003;74(I):1-30. DOI: $10.1080 / 000164702760300006$
6. Oryan A, Moshiri A, Meimandi-Parizi AH. Short and long terms healing of the experimentally transverse sectioned tendon in rabbits. Sports Med Arthrosc Rehabil Ther Technol. 2012;4:14-18. doi: $\underline{10.1186 / 1758-2555-4-14}$

7. Amin A, Davood S, Gholamreza A, Saeed H, Hamidreza F. Effect of platelet-rich plasma, low-level laser therapy or their combination on the healing of Achilles tendon in rabbits: a histopathological study. Eur J Experi Biol. 2014; 4(3):201-208. doi:www.pelagiaresearchlibrary.com.

8. Deese JM, Gratto-Cox G, Clements FD, Brown K. Achilles allograft reconstruction for chronic Achilles tendinopathy. J Surg Orthop Adv. 2015;24:75-78. doi: 10.3827/faoj.2016.0903.0008

9. Najafbeygi A, Fatemi MJ, Lebaschi AH, Mousavi SJ, Husseini SA, Niazi M. Effect of basic fibroblast growth factor on Achilles tendon healing in rabbit. World J Plast Surg. 2017;6(1):26-32. doi.org/10.1177/0363546519827947.

10. Peeters ME, Gil D, Teske E, Eyzenbach V, vd Brom WE, Lumeij JT, de Vries HW. Four methods for general anaesthesia in the rabbit: a comparative study. Laboratory Animals, 1988; 22 (4), 355-360. doi.org/10.1258/002367788780746197.

11. Fridman R, Rahimi F, Lucas P, Daugherty R, Hoffmann H. Repair of Neglected Achilles Tendon Rupture with Monofilament Polypropylene Mesh: A Case Study of 12 Patients. Foot Ankle J. 2008;1(5):2-7. doi: 10.3827/faoj.2008.0105.0002.

12. Bu rgisser MG, Calcagni M, Bachmann E, Fessel G, Snedeker GJ, Giovanoli P, Buschmann J. Rabbit Achilles tendon full transection model-wound healing, adhesion formation and biomechanics at 3,6 and 12 weeks post-surgery. Biol. 2016;5:1324-1333. doi: 10.1242/bio.020644.

13. Carriel V, Campos A, Alaminos M, Raimondo S, Geuna S. Staining methods for normal and regenerative myelin in the nervous system. Histochemistry of Single Molecules, 1560 of the series Methods in Molecular Biology; 2017. 207-218 p. doi: https://doi.org/10.1007/9781-4939-6788-9_15.

14. Lewis PK, Statistical Power, Sample Sizes, and the Software to Calculate Them Easily. BioScience. 2006 ; 56 (7):607-612. doi.org/10.1641/00063568(2006)56[607:SPSSAT]2.0.CO;2.

15. Voleti PB, Buckley MR, Soslowsky LJ. Tendon healing: repair and regeneration. Annu Rev Biomed Eng. 2012;14:4-8. doi: 10.1146/annurev-bioeng-071811-150122.

16. Maffulli N. Rupture of the Achilles tendon. J. Bone Joint Surg Am. 1999;81(7):1019-1036.doi: 10.2106/00004623-199907000-00017

17. Alfredson H, Bjur D, Thorsen K, Sandstrom P. High intratendinous lactate levels in painful chronic Achilles tendinosis. J Orthop Res. 2002;20:934-938.doi: 10.1016/S0736-0266(02)00021-9.

18. Truntzer JN, Triana B, Harris AH, Baker L, Chou L, Kamal RN. Costminimization analysis of the management of acute achilles tendon rupture. J Am Acad Orthop Surg. 2017;25:449-457.doi: 10.5435/JAAOS-D-16-00553.

19. Molloy A, Wood EV. Complications of the treatment of Achilles tendon ruptures. Foot Ankle Clin North Am. 2009;14(4):745759.doi.org/10.1016/j.fcl.2009.07.004.

20. Stavrou M. Treatment for Achilles tendon ruptures in athletes. Ortho J Bone Joint Surg. 2013;(21):232-239.doi: $10.1177 / 230949901302100224$.

21. Moores AP, Owen MR, Tarlton JF. The three-loop pulley suture versus two locking loop sutures for the repair of canine Achilles tendon. Vet Surg. 2004;33:131-137. doi: 10.1111/j.1532950x.2004.04020.x

22. Lawrence TM, Davis TR. A biomechanical analysis of suture and their influence on a four-strand flexor tendon repair. J Hand Surg. 2005;30:836-841.doi: 10.1016/j.jhsa.2005.03.011

23. Mario K, Ozre P, Kostesic D. Biomechanical and Histological indicators of Achilles tendon healing in rabbits. Vet Archie. 2011;81(2):223-233. doi: 10.1007/s00264-009-0778-1.

24. Maia L, Souza M V, Júnior J I. Platelet-Rich Plasma in the Treatment of Induced Tendinopathy in Horses: Histologic Evaluation. Journal of 
Equine Veterinary Science. 2009; 29(8): 618-626. https://doi.org/10.1016/j.jevs.2009.07.001

25. Dietrich F, Duré GL, Klein CP. Platelet-Rich Fibrin Promotes an Accelerated Healing of Achilles Tendon When Compared to PlateletRich Plasma in Rat. World J Plast Surg. 2015; 4(2): 101-109. doi: PMC4537601.

26. Márcia T, Rodrigues M, Rui L. Engineering tendon and ligament tissues: present developments towards successful clinical products. J Tissue Eng Regen Med. 2012;1(14):79-85.doi: 10.1002/term.1459.

27. Khazen GE, Wilson AN, Ashfaq S, Parks BG, Schon LC. Fixation of calcaneal avulsion fractures using screws with and without suture anchors: A biomechanical investigation. Foot Ankle Int. 2007;28(11):1183-1186.doi: 10.3113/FAI.2007.1183.

28. Liebermen JR, Lozman J, Dougerty J. Repair of achilles tendon ruptures with dacron vascular graft. J. Clin Orthop. 1988;234: 204208.doi: https://europepmc.org/abstract/med/2970358.

29. Aspenberg P. Stimulation of tendon repair: mechanical loading, GDFs and platelets. A mini-review. Int Orthop. 2007;31(6):783-789. doi: $10.1007 / \mathrm{s} 00264-007-0398-6$
30. Kuo CK, Tuan RS. Mechano-active tenogenic differentiation of mesenchymal stem cells. Tissue Eng. 2008;14(10):1615-1627. doi: 10.1089/ten.tea.2006.0415.

31. Sharma P, Maffulli N. Basic biology of tendon injury and healing. Surg. 2005;3(5):309-316. doi.org/10.1016/S1479-666X(05)80109-X.

32. Pufe T, Petersen WJ, Mentlein R, Tillmann BN. The role of vasculature and angiogenesis for the pathogenesis of degenerative tendons disease. Scand J Med Sci Sports. 2005;15(4):211-222. doi: 10.1111/j.1600-0838.2005.00465.x.

33. James R, Kesturu G, Balian G, Chhabra AB. Tendon: biology, biomechanics, repair, growth, factors and involving treatment options: a review. J Hand Surg Am. 2008;33:102-112. doi: 10.1016/j.jhsa.2007.09.007

34. Campbell EJ, Bailey JV. Mechanical properties of suture materials in vitro and after in vivo implantation. Vet. Surg. 1992;21:335-341. doi.org/10.1111/j.1532-950X.1992.tb01711.x. 